\title{
Infected delayed puerperal hematoma complicated by retention of urine: a case report and literature review
}

\author{
Tanjona A. Ratsiatosika ${ }^{1 *}$, Randriamahavonjy Romuald ${ }^{2}$, Faisoaly ${ }^{1}$, \\ Rainibarijaona A. Lantonirina ${ }^{1}$, Rakotonirina Martial ${ }^{1}$, Rakotonirina Ando-Miora ${ }^{1}$, \\ Andrianampanalinarivo H. Rakotovao ${ }^{1}$
}

\begin{abstract}
${ }^{1}$ Department of Public Health, Faculty of Medicine, Antananarivo, Madagascar
${ }^{2}$ Department of Obstetrics and Gynecology, Soavinandriana Hospital Center, Faculty of Medicine Antananarivo, Madagascar
\end{abstract}

Received: 17 April 2019

Revised: 13 May 2019

Accepted: 30 May 2019

\author{
*Correspondence: \\ Dr. Tanjona A. Ratsiatosika, \\ E-mail: ratsiatosika.tanjona@gmail.com
}

Copyright: (c) the author(s), publisher and licensee Medip Academy. This is an open-access article distributed under the terms of the Creative Commons Attribution Non-Commercial License, which permits unrestricted non-commercial use, distribution, and reproduction in any medium, provided the original work is properly cited.

\begin{abstract}
The puerperal hematoma corresponds to a tissue cleavage, most often paravaginal or vulvar, in which the vascular wounds, linked to the detachment, have no spontaneous tendency to haemostasis. The aggravation of this pathology is progressive. Diagnosis and management must be an obstetric emergency. Author report a case of infected puerperal hematoma complicated by rectal compression and acute retention of urine. This is a 26-year-old patient with a history of chronic hypertension. Labor was induced by misoprostol. The delivery was uneventful at 37 weeks vaginally. Ten days after delivery, she returned to the obstetrical emergency service for acute urine retention. The examination with the vaginal speculum showed a tumefaction of six centimeters on the left lateral side of the vagina. Surgical treatment has been performed. The suite was without particularity. The diagnosis of puerperal hematoma must be early. Even for the delayed form, the complications are identical. Blood loss, compression of proximity organs and infection are the most common complications. The care must be multidisciplinary. Resuscitation of the patient associated with haemostasis of the vessel is the main treatment in cases of large hematoma with hemodynamic instability.
\end{abstract}

Keywords: Postpartum hemorrhage, Puerperal hematoma, Puerperal infection, Urine retention

\section{INTRODUCTION}

The puerperal hematoma corresponds to a tissue cleavage, most often paravaginal or vulvar, in which the vascular wounds, linked to the detachment, have no spontaneous tendency to haemostasis. The aggravation of this pathology is progressive. The hematoma can develop in the retroperitoneum, the broad ligament and the ischiorectal space. ${ }^{1}$ The vascularity and congestion of the pelvic tissues and parturition predispose to tearing of vessels. ${ }^{2}$ The discovery of the puerperal thrombus may be immediate or in the days following delivery. The thrombus or vulvovaginal hematoma is a rare haemorrhagic complication ( 1 to 2 per 1,000 deliveries) occurring preferentially post-partum but also during pregnancy. Its prognosis, often favorable, perhaps in some cases, dramatic and may be life-threatening., ${ }^{3,4}$ The known risk factors are nulliparity, maternal age greater 
than 29 years old and a birth weight greater than $4 \mathrm{~kg} .{ }^{5}$ Other risks, such as instrumental extraction, multiple pregnancies, and coagulation problems, are suspected. ${ }^{6,7}$ Diagnosis and management must be an obstetric emergency. At first, the management is expectative if the hematoma is small. On the other hand, if the hematoma increases in volume, a surgical treatment would be necessary by the ligation of the vessels. ${ }^{8}$ Complications are numerous but acute retention of urine, rectal compression and infection of the hematoma are rare. We report here a case of infected puerperal hematoma complicated by rectal compression of acute retention of urine.

\section{CASE REPORT}

This is a 26-year-old patient with a history of chronic hypertension whose pregnancy has been well followed. Labor was induced by misoprostol. The delivery was uneventful at 37 weeks vaginally after 7 hours of labour and gives birth of a $2200 \mathrm{~g}$ fetus in meconium amniotic fluid. The fetal presentation was cephalic. there was no instrumental extraction or episiotomy. There was no immediate postpartum hemorrhage, hematoma, or traumatic injury, and the uterus was well retracted. The postpartum period was uneventful and the patient was discharged two days later. Ten days after delivery, she returned to the obstetrical emergency service for acute urine retention for 12 hours, tenesm, vaginal pain and dysuria. She also complained constipation evolving for 5 days. Everything was evolving in a feverish context. At the admission, there was a cutaneous pallor, a blood pressure at $140 / 80 \mathrm{mmHg}$, a heart rate at $90 / \mathrm{min}$, a respiratory rate at $23 / \mathrm{min}$ and a temperature of $38^{\circ} \mathrm{C}$. On physical examination, we found a bladder globe with apparently normal and symmetrical vulva. The examination with the vaginal speculum showed a tumefaction of six centimeters on the left lateral side of the vagina (Figure 1) which was sensitive and hard to the vaginal touch. In the rectal examination, a painful tumefaction was seen on the lateral wall of the rectum with an empty rectal touch. There was no defense and rebound during abdominal examinations. The rest of the exam was normal.

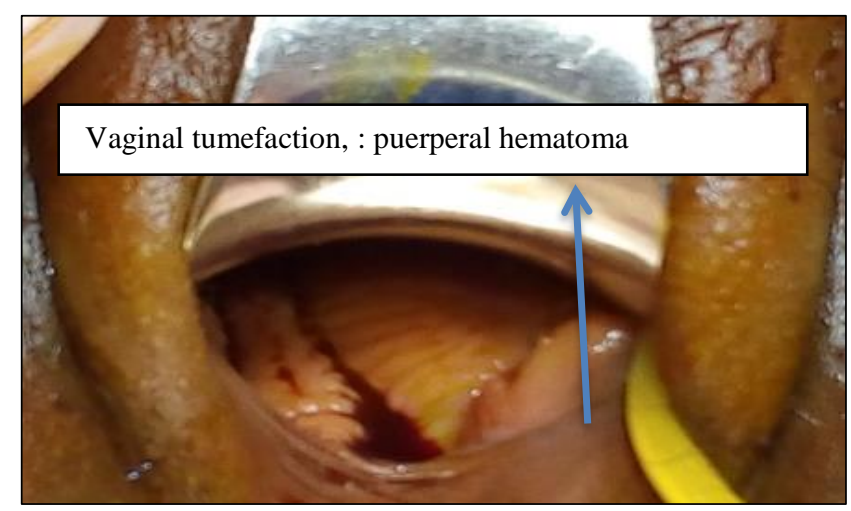

Figure 1: Vaginal examination.
The blood cell count found an anemia with haemoglobin level at $70 \mathrm{~g} / \mathrm{L}$ with a $40 \mathrm{~g} / \mathrm{dl}$ decrease in hemoglobin compared to the previous value, a predominantly neutrophilic hyperleucocytosis at $16.5 \mathrm{G} / \mathrm{L}$ and a normal platelet count. CRP increased to $192 \mathrm{mg} / \mathrm{L}$. The renal function was normal. The abdominopelvic ultrasound was normal. Blood culture, cytobacteriological examination of the urine were not available urgently.

The diagnosis was an infected vulvovaginal hematoma complicated by acute retention of urine and rectal compression.

A bladder catheter was set up allowing the evacuation of about 450cc of urine for thrombus evacuation under general anesthesia was performed in the operating room. The incision was made at the level of nympho-hymeneal junction (Figure 2) and more than $250 \mathrm{ml}$ of blood with thrombotic and purulent debris was externalized (Figure 3). Abundant and cleansingwith physiological saline and polyvidone and Delbet drain placement were performed for 48 hours (Figure 4). A packing was left in the vagina with compressive wound dressing for 24 hours.

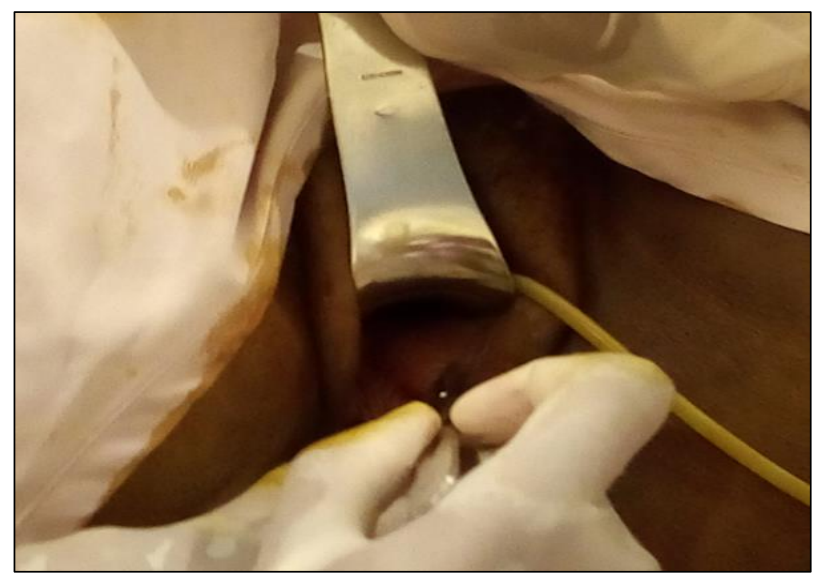

Figure 2: Vaginal incision at the level of nymphohymeneal Juntion.

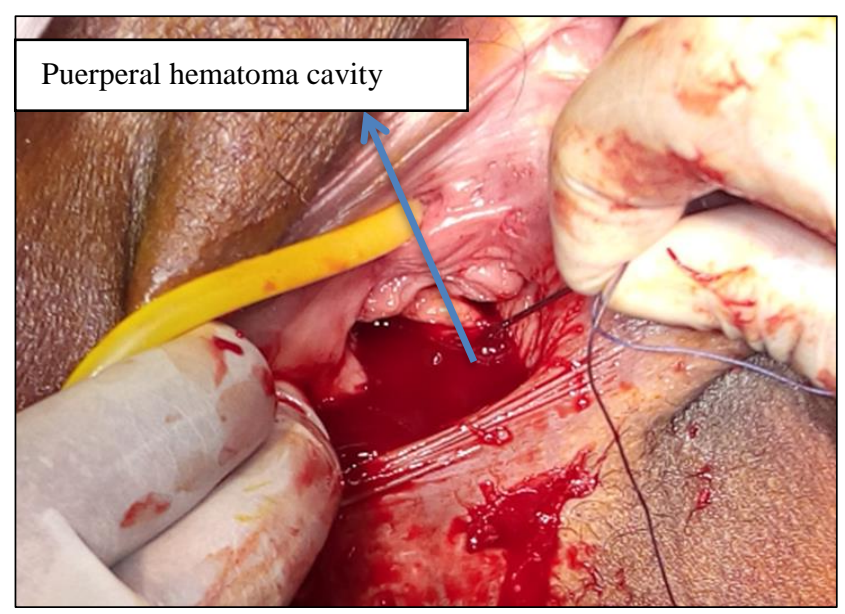

Figure 3: Hematoma evacuation. 


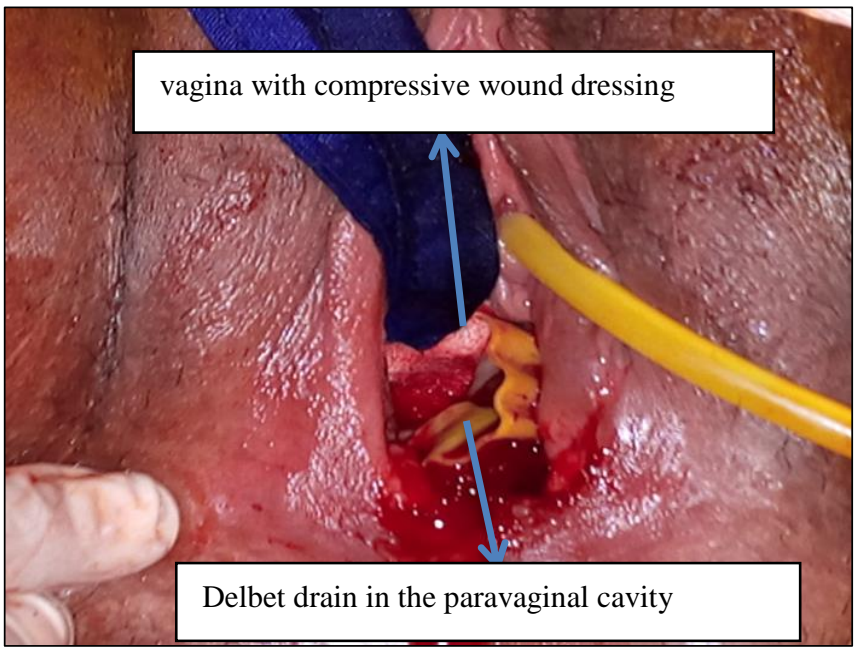

Figure 4: Vaginal appearence at the end of surgical treatment.

Antibiotherapy with ceftriaxone, metronidazole and gentamycin has been initiated. Oral iron supplementation has been prescribed.

The patient was discharged after four days of hospitalization and the Delbet drain was removed after 48 hours of surgery. The suite was without particularity. The patient was discharged on the fifth postoperative day.

\section{DISCUSSION}

Puerperal hematoma is a rare haemorrhagic complication (1 in 1,000 deliveries) that occurs preferentially in post partum but may occur during pregnancy. ${ }^{9}$ In contrast, in 2005 , Delaby et al, reported a case of vulvar thrombus occurring in per partum at 37 weeks of amenorrhea after speculum placement during an antenatal consultation. ${ }^{4}$ In our case, it is a delayed hematoma. The chronological classification makes it possible to describe an immediate hematoma occurring just after delivery following an obstetrical trauma and a delayed hematoma most often discovered a few days, or even a few weeks after delivery, secondary to either a necrosis by hyperpressure of the pelvic vessels or a slow evolution of an early hematoma not previously recognized. In case of vaginal hematoma, the external examination is often normal in the absence of a vaginal or rectal touch. It is even possible to miss the diagnosis until emergence of complications. ${ }^{10}$

To our knowledge, we reported the first case of puerperal hematoma that occurs after a long latency period (10 days). Kehila et al, reported a case of vulvovaginal thrombus occurring after the fifth day postpartum. ${ }^{11}$ For Rani et al, the discovery of the hematoma occurs within 24 hours after delivery with an average of six hours. ${ }^{12}$

The risk factors for puerperal hematoma recognized in the literature are: primiparity, instrumental extraction, preeclampsia, twin pregnancies, episiotomy, prolonged labor, fetal macrosomia.-7 For Rani et al, high blood pressure during pregnancy is a risk factor for puerperal hematoma. ${ }^{12}$ In our case, it is the primiparity and the chronic hypertension which constitute the risk factors for the occurrence of puerperal hematoma. Saleem et al, found that primiparity increases the risk of puerperal hematoma by three times with OR 3.63 (95\% CI 3.254.08)..$^{5}$

The acute retention of urine was the main symptom in our case. The pain was present but bearable. In the literature, this is the first sign of puerperal hematoma. ${ }^{10,13}$ But in all cases, the diagnosis remains clinical. The association of vulvovaginal pain, hemodynamic disorders and perineal or vaginal tumefaction leads to the diagnosis. ${ }^{6}$ Acute retention of urine remains a rare complication especially during specific anatomical localizations of the hematoma. Fieni et al reported a case of puerperal hematoma in the Retzius space that was complicated by urine retention. ${ }^{14}$ Imaging exams are reserved for particular forms such as retroperitoneal localization, deep localization. These examinations also make it possible to monitor the evolution of the lesions in case of expectant treatment. MRI remains the first-line examination for puerperal hematoma. But if the exam is not available, the TDM can be enough. Finally, the identification of the responsible vessels would be easy with the imaging examinations. ${ }^{6}$

Regarding the care, it is a multidisciplinary care. The obstetrician, the anaesthetists and the radiologist are involved. It can be expectative if the size is less than 5 $\mathrm{cm}^{6}$ Villella et al, suggest this strategy up to $8 \mathrm{~cm}$, If the size is greater than $10 \mathrm{~cm}$, active care must be taken. ${ }^{15,16}$ For some authors, it is the hemodynamic state of the patient that dictates management. Even for large hematomas without repercussions on the hemodynamic state, an expectant treatment may be proposed. ${ }^{11}$

The treatment may be surgical or by arterial embolization. Surgical treatment is based on clot evacuation, haemostasis, drain placement and vaginal tamponade. A urinary catheter must be put in place to prevent urinary retention by urethral compression. ${ }^{6}$ Arterial embolization involves identifying the origin of bleeding and is based on the selective embolization of vaginal arteries. ${ }^{17}$ The efficacy of this treatment is $90 \%$ to $100 \% .{ }^{18}$ However, few centers have access to this technique urgently. ${ }^{19}$

If hemorrhage persists, embolization or ligation of the hypogastric artery is necessary. ${ }^{6}$ In our context, surgical treatment remains the treatment of choice in the treatment of puerperal hematomas. The deglobulization and the compression effect by the hematoma led us to treat the patient urgently.

\section{CONCLUSION}

To conclude, the diagnosis of puerperal hematoma must be early. Even for the delayed form, the complications 
are identical. Blood loss, compression of proximity organs and infection are the most common complications. The care must be multidisciplinary. Resuscitation of the patient associated with haemostasis of the vessel is the main treatment in cases of large hematoma with hemodynamic instability. Hemostasis can be surgical or interventional radiology.

Funding: No funding sources

Conflict of interest: None declared

Ethical approval: Not required

\section{REFERENCES}

1. Monnier BP, Barbarino A, Bayoumeu F, Mezeray BV, Judlin P. Serious hemorrhages during pregnancy and postpartum; hemorrhagic shock. EMC Obstetrics. 1998;1-11.

2. Pedowitz P, Pozner S, Adler NH. Puerperal hematomas: analysis of 112 cases with a review of the literature. Am J Obstet Gynecol. 1961;81(2): 350-60.

3. Jewett JF. Fatal laceration from normal birth. N Engl J Med. 1972;287(1):44-5.

4. Delaby B, Guffroy MP, Lanta S, Najas S, Gagneur $\mathrm{O}$, Gondry J. Management of vulvar thrombus in per and post partum. J Gynecol Obstet Biol Reprod. 2006;35(1):94-5.

5. Saleem Z, Rydhstrom H. Vaginal hematoma during parturition: a population-based study. Acta Obstet Gynecol Scand. 2004;83(6):560-2.

6. Pailleux BJ, Huissoud C, Dubernard G, Rudigoz RC. Management of puerperal hematomas. J Gynecol Obstet Biol Reprod. 2009;38(3):203-8.

7. Guerriero S, Ajossa S, Bargellini R, Amucano G, Marongiu D, Melis GB. Puerperal vulvovaginal hematoma: sonographic findings with MRI correlation . J Clin Ultrasound. 2004;32(8):415-8.

8. Puerperal hematomas. In: Cunningham FG, Leveno KJ, Bloom SL, Spong CY, Dashe JS, Hoffman BL, editors. Williams obstetrics. 24 $4^{\text {th }}$ ed. New York: McGraw-Hill Education; 2014: 790e1.

9. Riethmuller D, Jeannin PC, Rabenja CA, Koeberle P, Schaal JP, Maillet R. A rare cause of postpartum hemorrhage: a genital thrombus. J Gynecol Obstet Biol Reprod. 1997;26(2):154-8.
10. Jacquetin B, Boulleret C, Fatton B. Genital thrombus. Extract Updates Gynecol Obs. 1998;XXII:347-65.

11. Kehila M, Kheder SB, Zeghai D, Mahjoub S. Conservative management of large volume puerperal hematomas: about 3 cases. Pan Afr Med J. 2013;16(9):1918.

12. Rani S, Verma M, Pandher DK, Takkar N, Huria A. Risk factors and incidence of puerperal genital haematomas. J Clin Diag Res. 2017;11(5):QC01-03.

13. Fouelifack FY, Fouogue JT, Fouedjio JH, Sando Z, Mbu RE. Massive postpartum vulvar hematoma: about a case at Yaoundé Central Hospital (Cameroun). Pan Afr Med J. 2014;19:167.

14. Fieni S, Berretta R, Merisio C, Melpignano M, Gramellini D. Retzius' space haematoma after spontaneous delivery: a case report. Acta Biomed. 2005;76(3):175-7.

15. Villella J, Garry D, Levine G, Glanz S, Figueroa R, Maulik D. Postpartum angiographic embolization for vulvovaginal hematoma: a report of two cases. J Reprod Med. 2001;46:65-7.

16. Propst AM, Thorp JM. Traumatic vulvar hematomas: conservative versus surgical management. South Med J. 1998;91(2):144-6.

17. Gentric JC, Koch G. Diagnosis and management of puerperal hematomas: two cases. endovascular approach is minimally invasive, effective, and permits future pregnancy. Cardiovasc Intervent Radiol. 2013;36(4):1174-6.

18. Pelage JP, Laissy JP. Prise in charge of severe postpartum haemorrhage: indications and techniques of arterial embolization. J Radiol. 2006;87(5):53340.

19. Takagi K, Akashi K, Horiuchi I, Nakamura E, Samejima K, Ushijima $J$, et al. Managing vulvovaginal hematoma by arterial embolization as first-line hemostatic therapy. Taiwan J Obstet Gynecol. 2017;56(2):224-6.

Cite this article as: Ratsiatosika TA, Romuald R, Faisoaly, Lantonirina R, Martial R, Ando-Mioral R, et al. Infected delayed puerperal hematoma complicated by retention of urine: a case report and literature review. Int J Reprod Contracept Obstet Gynecol 2019;8:2881-4. 